\title{
Emergency reconstructive endovascular management of intraoperative complications involving the internal carotid artery from trans-sphenoidal surgery
}

\author{
Julius Griauzde, ${ }^{1}$ Joseph J Gemmete, ${ }^{2,3,4}$ Aditya S Pandey, ${ }^{2,3}$ Erin L McKean, ${ }^{3,4}$ \\ Stephen E Sullivan, ${ }^{3,4}$ Neeraj Chaudhary ${ }^{2,3}$
}

${ }^{1}$ Department of Radiology, University of Michigan, Ann Arbor, Michigan, USA ${ }^{2}$ Division of Neurolnterventional Radiology, Department of Radiology, University of Michigan Health System, Ann Arbor, Michigan, USA ${ }^{3}$ Department of Neurosurgery, University of Michigan Health System, Ann Arbor, Michigan, USA

${ }^{4}$ Cranial Base Surgery Program, Department of Otolaryngology, University of Michigan Health System, Ann Arbor, Michigan, USA

\section{Correspondence to} Dr Joseph J Gemmete, University of Michigan Health System, Division of

Neurolnterventional Radiology, Department of Radiology, UH B1 D328, 1500 E Medical Center Drive, Ann Arbor, MI 48109, USA; gemmete@med.umich.edu

Received 16 July 2013 Revised 4 November 2013 Accepted 10 December 2013 Published Online First 9 January 2014

\section{CrossMark}

\section{To cite: Griauzde J,} Gemmete JJ, Pandey AS, et al. J Neurolntervent Surg 2015;7:67-71.

\section{ABSTRACT}

Purpose To report our experience with intraoperative complications involving the internal carotid artery (ICA) during trans-sphenoidal surgery and their outcome with reconstructive endovascular management.

Methods A retrospective review was conducted of patients with an ICA injury related to trans-sphenoidal surgery from 2000 to 2012. Demographic data, clinical charts, indications for treatment, radiographic images, lesion characteristics, operative notes, endovascular procedure notes and post-procedure hospital course were reviewed.

Results Three men and one woman of mean age of 52 years (range 33-74) were identified. The lesions included two macroadenomas, one meningioma and one chondrosarcoma. Risk factors for ICA rupture included two patients with carotid dehiscence, one with sphenoid septal attachment to the ICA, two with revision surgery, one with prior radiation to the tumor, one with bromocriptine treatment and two with acromegaly. In three patients, covered stent placement achieved hemostasis at the site of injury within the ICA. One patient developed delayed bleeding $6 \mathrm{~h}$ after covered stent placement and underwent successful endovascular occlusion of the ICA but died 6 days after the injury. The fourth patient had an intraoperative ICA stroke requiring suction thrombectomy, thrombolysis, stent placement and evacuation of an epidural hematoma. At 1-year follow-up, two patients had a modified Rankin score (mRS) and National Institute of Health Stroke Scale (NIHSS) score of 0 ; in the patient who had a stroke the mRS score was 1 and the NIHSS score 2 .

Conclusions Endovascular management with arterial reconstruction is helpful in the treatment of ICA injuries during trans-sphenoidal surgery.

\section{INTRODUCTION}

Intraoperative injuries of the internal carotid artery (ICA) have a high morbidity and mortality when they occur during trans-sphenoidal surgery. ${ }^{12}$ The presentation of this potentially fatal complication includes severe perioperative or postoperative bleeding, a false aneurysm of the ICA or a carotid cavernous fistula. ${ }^{3}$ Immediate diagnosis and treatment of these complications is essential to maximize patient survival. Traditionally, surgical ligation or endovascular occlusion of the ICA has been used to treat ICA injuries; however, surgical ligation is associated with a high incidence of major complications. ${ }^{4}$ Because of these complications, endovascular occlusion has become the preferred treatment for ICA injuries. A balloon test occlusion must be performed prior to sacrifice of the ICA. If the patient does not tolerate a balloon test occlusion, then a surgical bypass or reconstructive endovascular procedure should be performed.

In this paper we present our experience with intraoperative complications involving the ICA during trans-sphenoidal surgery and their outcome with reconstructive endovascular management.

\section{METHODS}

A retrospective review was conducted of patients with a carotid injury related to trans-sphenoidal surgery from 2000 to 2012. Patient demographic data, clinical charts, indications for treatment, radiographic images, lesion characteristics, operative notes, endovascular procedure notes and the post-procedure hospital course were reviewed. All patients were examined by a neurosurgeon or interventional neuroradiologist after treatment and then at 3,6 and 12 months.

Informed consent was obtained from the patient or legal representative for the use of a covered stent, including its off-label use. All procedures were performed under general anesthesia and intraoperative neuromonitoring with electroencephalography (EEG) and somatosensory evoked potentials (SSEPs). The patient was immediately transferred to the angiographic suite after the surgeon noticed injury to the distal ICA or loss of intraoperative neuromonitoring signals. The operative site was packed in an attempt to maintain hemostasis prior to transfer and the surgical site was not closed. Patients were supported with appropriate blood products and intravenous fluids during transfer with continuous monitoring of vital signs.

In patients with suspected injury to the ICA, the authors believed the quickest approach to hemostasis was by an endovascular method, given that a craniotomy to expose the vessel and trap the area of injury would require at least $2 \mathrm{~h}$. The common femoral artery was punctured retrograde under ultrasound guidance for placement of a $5 \mathrm{~F}$ sheath. Cervical and cerebral digital subtraction angiography identified or confirmed the site of extravasation, vessel compromise, collateral circulation or a false aneurysm.

In three patients, once the area of extravasation was identified, a $300 \mathrm{~cm}$ Amplatz guidewire (Boston Scientific, Natick, Massachusetts, USA) was 
advanced into the ICA/external carotid artery (ECA) and the existing sheath exchanged for a $90 \mathrm{~cm} 7 \mathrm{~F}$ sheath (Cook, Bloomington, Indiana, USA) which was advanced into the distal cervical ICA over a 0.035 glidewire (Terumo, Somerset, New Jersey, USA). The area of extravasation in these three patients was in the distal cavernous segment of the ICA just below the ophthalmic artery. A $115 \mathrm{~cm} 0.072$ Navien guide catheter (ev3, Irvine, California, USA) was then placed coaxially through the sheath and advanced into the proximal aspect of the cavernous segment of the ICA under roadmap guidance. Through the guide catheter, a SL-10 microcatheter was advanced over a Synchro 14 wire (Stryker Neurovascular, Fremont, California, USA) under biplane roadmap guidance into the distal middle cerebral artery (MCA) or anterior cerebral artery (ACA). The wire was then exchanged for a $300 \mathrm{~cm} 0.014$ Balance Middle Weight (BMW) wire (Abbott, Santa Clara, California, USA). Using repeat angiography and roadmap guidance, a $4 \times 12 \mathrm{~mm}$ covered stent (Jostent graftmaster stent; Abbott) was placed across the area of extravasation within the cavernous segment of the ICA in two patients (patients 1 and 2) and a $4.5 \times 16 \mathrm{~mm}$ covered stent (Jostent) was placed in the third patient (patient 3). Heparin was titrated during the procedure to achieve an activated clotting time 2-2.5 times that of the baseline. Patients were loaded with $325 \mathrm{mg}$ aspirin and $600 \mathrm{mg}$ clopidogrel (Plavix, Sanofi-Synthelabo, Bridgewater, New Jersey, USA) just prior to stent placement. Once hemostasis was obtained, all three patients were transferred back to the operating theater for further resection of the tumor.

In the fourth patient, during tumor resection there was a dramatic decrease in the left hemispheric EEG and SSEPs. The patient was transferred to the angiography suite as an emergency. Left common carotid angiogram demonstrated poor antegrade flow within the left ICA, with severe extrinsic narrowing of the supraclinoid ICA from the tumor and a filling defect within the left M1 segment of the MCA. This patient had previously failed a balloon test occlusion, so suction thrombectomy of the MCA was performed with a 0.054 inch suction catheter (Penumbra, Alameda, California, USA) with some improvement in flow. The patient subsequently received $10 \mathrm{mg}$ intra-arterial tissue plasminogen activator (tPA; Genetech, San Francisco, California, USA) and $7 \mathrm{mg}$ abciximab (Reopro; Eli Lilly, Indianapolis, Indiana, USA) resulting in a Thrombolysis In Cerebral Infarction (TICI) score of 3 within the left MCA. A $4 \times 20 \mathrm{~mm}$ Wingspan stent (Stryker Neurovascular) was placed across the area of narrowing in the ICA and post-dilated with a $3 \times 15 \mathrm{~mm}$ Gateway balloon (Stryker Neurovascular). A repeat left ICA angiogram showed thrombosis of the stent with poor antegrade flow into the left MCA. The patient was given an additional intra-arterial dose of $10 \mathrm{mg}$ tPA and $7 \mathrm{mg}$ abciximab at the site of the thrombus. A repeat left ICA angiogram showed a widely patent left ICA filling the left MCA territory with a TICI score of 3.

Dual antiplatelet therapy was continued for 3 months in the three living patients, with a follow-up angiogram confirming the patency of the stents. Patients were continued on $81 \mathrm{mg}$ aspirin for life. The modified Rankin Scale score (mRS) and National Institute of Health Stroke Score (NIHSS) were calculated in the immediate postoperative period, at 3 months follow-up and then at 1 year.

\section{RESULTS}

The patient population included three men and one woman with a mean age of 52 years (range 33-74). Two patients had a pituitary macroadenoma, one had a meningioma and one had a
Table 1 Patient characteristics

\begin{tabular}{|c|c|c|c|}
\hline $\begin{array}{l}\text { Patient } \\
\text { no }\end{array}$ & Age & Tumor type & $\begin{array}{l}\text { Prior } \\
\text { resection }\end{array}$ \\
\hline 1 & $60 \mathrm{~s}$ & Pituitary macroadenoma & No \\
\hline 2 & $30 \mathrm{~s}$ & $\begin{array}{l}\text { Subfrontal meningioma with extension into } \\
\text { the sella suprasellar region }\end{array}$ & Yes \\
\hline 3 & $70 \mathrm{~s}$ & Pituitary macroadenoma & No \\
\hline 4 & $30 \mathrm{~s}$ & Suprasellar chondrosarcoma & Yes \\
\hline
\end{tabular}

chondrosarcoma. The patients with a macroadenoma presented with polyarthropathy, acromegaly and visual changes. The patient with a meningioma initially underwent partial resection and radiation therapy of the tumor at 10 years of age and presented with rhinnorhea and periodic heavy epistaxis. The patient with a recurrent chondrosarcoma had two prior resections of the tumor and also presented with long-standing visual changes. Operative excision of the chondrosarcoma was attempted to try and prevent further deterioration of the patient's vision. The clinical characteristics of the patients are summarized in table 1. Risk factors for ICA rupture in this series included two patients with carotid dehiscence, one with sphenoid septal attachment to the ICA, two with revision surgery, one with prior radiation to the tumor, one with bromocriptine treatment and two with acromegaly. No patients had preoperative imaging demonstrating an ICA aneurysm. Procedural details are summarized in table 2. Stent placement was technically successful in all patients. Immediate hemostasis was obtained following covered stent placement in all three patients; however patient 3 developed delayed bleeding $6 \mathrm{~h}$ after stent placement and underwent parent vessel sacrifice with coils after passing a temporary balloon test occlusion. This patient subsequently developed a large acute stroke in the territory of the ICA occlusion and died on postoperative day 6 . Patient 1 returned to the angiographic suite 3 days later for placement of a $4 \times 12 \mathrm{~mm}$ bare metal stent (Integrity; Medtronic, Minneapolis, Minnesota, USA) to improve apposition of the covered stent along the lesser curve of the cavernous ICA. This was performed to reduce the risk of thromboembolic complications and possible late leakage from the lacerated ICA. At 1-year follow-up, the two living patients had mRS and NIHSS scores of 0 with no recurrence of hemorrhage or a recurrent stenosis.

Table 2 Procedural details

\begin{tabular}{|c|c|c|c|c|}
\hline $\begin{array}{l}\text { Case } \\
\text { number }\end{array}$ & $\begin{array}{l}\text { ICA } \\
\text { complication }\end{array}$ & Treatment & Follow-up & $\begin{array}{l}\text { Long-term } \\
\text { outcome }\end{array}$ \\
\hline 1 & $\begin{array}{l}\text { Vessel } \\
\text { perforation }\end{array}$ & Covered stent & 1 year & $\begin{array}{l}\text { mRS } 0 \\
\text { NIHSS } 0\end{array}$ \\
\hline 2 & $\begin{array}{l}\text { Vessel } \\
\text { perforation }\end{array}$ & Covered stent & 1 year & $\begin{array}{l}\text { mRS } 0 \\
\text { NIHSS } 0\end{array}$ \\
\hline 3 & $\begin{array}{l}\text { Vessel } \\
\text { perforation }\end{array}$ & Covered stent & N/A & $\begin{array}{l}\text { Death } 6 \text { days } \\
\text { after treatment }\end{array}$ \\
\hline 4 & $\begin{array}{l}\text { Intraoperative } \\
\text { stroke }\end{array}$ & $\begin{array}{l}\text { Wingspan stent } \\
\text { placement, } \\
\text { Penumbra, tPA, } \\
\text { abciximab }\end{array}$ & 1 year & $\begin{array}{l}\text { mRS } 1 \\
\text { NIHSS } 2\end{array}$ \\
\hline
\end{tabular}

ICA, internal carotid artery; mRS, modified Rankin Scale; NIHSS, National Institute of Health Stroke Scale; tPA, tissue plasminogen activator. 
Patient 4 had narrowing and thrombosis of the ICA which was successfully revascularized. After revascularization the patient began bleeding from the oropharynx and the surgical site related to the intra-arterial tPA, abciximab and the dual antiplatelet agents used during restoration of flow within the ICA. CT of the brain performed in the angiography suite showed new subarachnoid, epidural and intraparenchymal hemorrhage with a $15 \mathrm{~mm}$ midline shift to the right. The patient underwent a left frontotemporal craniectomy for evacuation of the epidural hematoma. In the acute postoperative period the patient had an NIHSS score of 7 and a diffusion-weighted MRI showed an area of acute ischemia in the left basal ganglia and insular cortex. At 3-month follow-up the patient's NIHSS score improved to 2 and the stent placed within the ICA segment and left MCA were widely patent. At 1-year follow-up the mRS score was 1 with an NIHSS score of 2 .

\section{CASE EXAMPLE}

A 60-year-old patient presented with clinical manifestations of acromegaly and was found on imaging to have a right-sided pituitary macroadenoma (figure 1A). During stealth-guided endoscopic trans-sphenoidal resection, the tumor was seen partially surrounding the right ICA. During skeletonization of the right cavernous sinus region an injury occurred to the right ICA at the superior aspect of the cavernous sinus. The area was immediately packed and the patient was transferred to the angiographic suite. A diagnostic angiogram demonstrated injury in the distal cavernous segment of the right ICA (figure 1B). A $4 \times 12 \mathrm{~mm}$ Jostent graftmaster (Abbott) was advanced over a wire and placed at the site of extravasation off the ICA. It was not possible to spare the ophthalmic artery given the proximity of the injury. The proximal portion of the stent along the lesser curve of the cavernous bend did not conform to the vessel wall (figure 1C). The patient returned to the operating room and, upon resumption of tumor removal, there was no evidence of carotid bleeding. The tumor was removed in its entirety. The patient returned 3 days later for repeat stent placement for improved apposition along the lesser curve of the cavernous bend (figure 1D). At 1-year follow-up the patient had mRS and NIHSS scores of 0 .

\section{DISCUSSION}

Iatrogenic ICA injury during trans-sphenoidal surgery is a rare complication occurring in approximately $0.2-1 \%$ of cases. ${ }^{15} 6$ Several factors have been identified that increase the risk of this complication, including acromegaly, intimate association of the lesion with the ICA, reoperation, prior radiation therapy, bromocriptine therapy, extensive calcification and carotid artery anomalies. ${ }^{1} 3^{7-10}$ By altering the regional anatomy and causing fibrotic changes, these factors make surgical resection significantly more challenging. When the ICA is damaged intra-operatively, emergency management is paramount to minimize morbidity and mortality. In this report we present our experience with injury to the ICA during trans-sphenoidal surgery and emergency reconstructive endovascular management. Our results indicate that endovascular reconstruction of the ICA can lead to positive outcomes in these cases.

In our first three cases, ICA vessel laceration was encountered during surgical resection. Initial management of hemorrhagic ICA injury focuses on bleeding control with extensive packing
Figure 1 (A) Coronal MRI post-contrast T1-weighted image showing a macroadenoma adjacent to the right cavernous carotid artery (yellow arrow). (B) Anteroposterior right internal carotid angiogram (RICA) showing extravasation of contrast from the distal cavernous segment of the right internal carotid artery (yellow arrow). (C) Anteroposterior RICA after Jostent placement showing no contrast extravasation. Incidental note is made of a middle cerebral artery aneurysm which was later clipped. (D) Sagittal Dyna CT image showing improved apposition of the Jostent with the vessel wall (yellow arrow shows area of overlap of the stents).
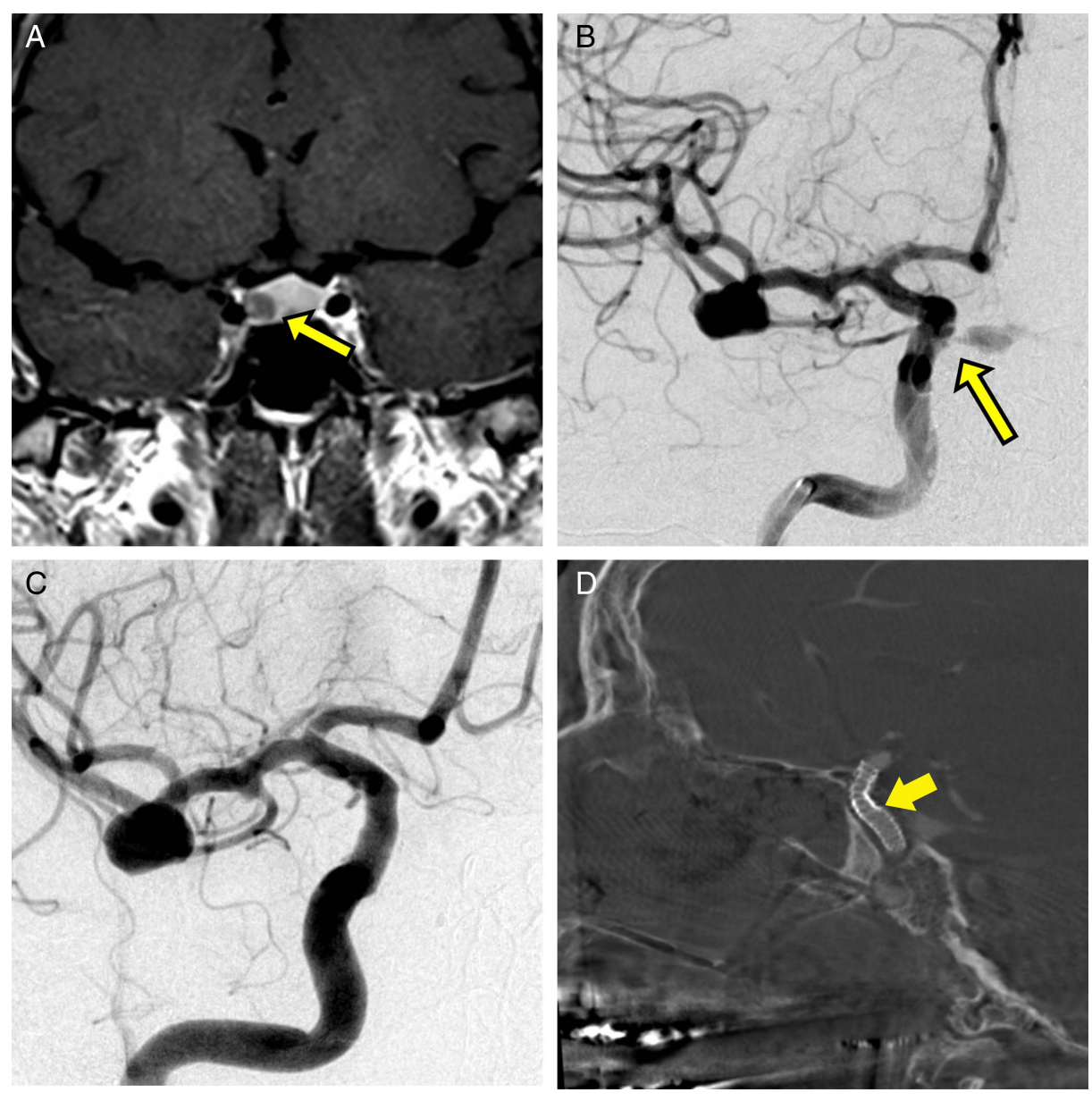
of the site and manual compression of a more proximal vessel, followed by surgical or endovascular vessel occlusion (if the patient has tolerated occlusion testing) or vessel reconstruction. ${ }^{311-14}$ In our cases, hemostasis was achieved with endovascular covered stent placement. Covered stent placement has been reported as a viable option for iatrogenic ICA injury in patients who cannot tolerate ICA occlusion. ${ }^{67912} 13$ This technique is probably superior to open or endovascular vessel occlusion since, even if the patient has tolerated the balloon test occlusion, there is still a risk of ischemic complications. ${ }^{3}$ Two of our patients had excellent long-term outcomes. The third had persistent hemorrhage which was treated with technically successful ICA occlusion but he died despite passing balloon occlusion testing.

Although covered stent placement provides a valuable option in cases of ICA injury, it is not without limitations. Undesired outcomes include difficulty with stent apposition with the vessel wall, carotid vasospasm and undesired vessel coverage. In patient 1 we experienced incomplete apposition of the stent to the vessel wall secondary to vessel tortuosity. This was managed in the subacute period with subsequent stent placement, although coil embolization to fill in the gap between the stent and vessel wall is an alternative. ${ }^{7}$ Patient 3 had recurrent bleeding from the ICA which was also most likely due to poor apposition of the covered stent on the vessel wall in conjunction with dual platelet therapy. An additional complication that has been reported is carotid vasospasm which is postulated to occur with balloon expansion of the stent. ${ }^{9}{ }^{15}$

Patient 4 had an intraoperative ischemic stroke. This was further complicated by in-stent thrombosis and intracranial hemorrhage. We hypothesize that the initial ischemic event was a result of a combination of operative manipulation of the vessel and extrinsic tumor compression as the vessel was not surgically damaged. Our initial attempts at suction thrombectomy with the Penumbra system were only partially successful and required administration of tPA and abciximab for complete thrombus clearance. Stent placement was subsequently performed due to severe narrowing of the ICA by the tumor mass. Unfortunately, thrombosis reoccurred and further treatment with balloon angioplasty and additional intra-arterial administration of tPA and abciximab was needed for resolution of the thrombus. This subsequently led to an epidural hematoma which required evacuation. Despite the complicated procedural course, this patient had an excellent outcome with an mRS score of 1 and an NIHSS score of 2 at 1 year. The authors thought that aggressive treatment of this patient was warranted given his young age (29) and lack of medical comorbidities. The authors believe that some caution should be used in administering thrombolytic and multiple antiplatelet agents in an acute stroke; however, in certain cases this form of aggressive treatment may provide an excellent outcome. There are at least three reports of abciximab in conjunction with a fibrinolytic agent being effective in acute clot dissolution and in the combined treatment (with balloon angioplasty) of acute in-stent thrombosis. ${ }^{16-18}$ Our experience supports its usage in these acute occurrences.

A single case reports the novel use of the Pipeline embolization device (PED; Covidian, Irvine, California, USA) for successful obliteration of a traumatic pseudoaneurysm resulting from intraoperative injury during endoscopic sinus surgery. ${ }^{19}$ Complete exclusion of the pseudoaneurysm at the 4-month follow-up angiogram supports the possible durability of PED repair achieving endoluminal reconstruction of the damaged vessel. A limitation of the PED is that decreased flow into aneurysms may not provide immediate thrombosis, and it may take a number of weeks for complete occlusion. This may leave a patient at risk of rupture during this interim period.

In the three cases in which a covered stent was placed, the surgeon thought that returning the patient to the operating room was necessary to determine if hemostasis had been obtained. Furthermore, given the initial difficult surgical exposure, the surgeon thought further excision of the tumor would be of minimal risk to the patient even with the use of dual antiplatelet agents. If during the surgical excision hemostasis was difficult to maintain, the surgical plan was to stop the procedure and administer platelets.

Our study is limited by the small cohort size and its retrospective nature. Although our results are promising, we recommend careful evaluation on a case-by-case basis to ensure that the appropriate treatment is employed and poor outcomes are avoided.

\section{CONCLUSION}

ICA injuries during trans-sphenoidal surgery can have a dire outcome if they are not managed in a definitive and timely manner. Emergency endovascular management with arterial reconstruction is helpful in the treatment of these difficult cases.

Contributors JG, JJG, NC, ASP, ELM and SES all contributed to writing, editing and data collection for the manuscript.

Competing interests None.

Ethics approval Ethics approval was obtained from the Institution Review Board.

Provenance and peer review Not commissioned; externally peer reviewed.

\section{REFERENCES}

1 Ciric I, Ragin A, Baumgartner C, et al. Complications of transsphenoidal surgery: results of a national survey, review of the literature, and personal experience. Neurosurgery 1997:40:225-36

2 Oskouian RJ, Kelly DF, Laws ER Jr. Vascular injury and transsphenoidal surgery. Front Horm Res 2006;34:256-78.

3 Raymond J, Hardy J, Czepko R, et al. Arterial injuries in transsphenoidal surgery for pituitary adenoma; the role of angiography and endovascular treatment. AJNR Am J Neuroradiol 1997:18:655-65.

4 Chaloupka JC, Putman CM, Citardi MJ, et al. Endovascular therapy for the carotid blowout syndrome in head and neck surgical patients: diagnostic and managerial considerations. AJNR Am J Neuroradiol 1996;17:843-52.

5 Gondim JA, Almeida JP, Albuquerque LA, et al. Endoscopic endonasal approach for pituitary adenoma: surgical complications in 301 patients. Pituitary 2011;14:174-83.

6 Berker M, Hazer DB, Yucel T, et al. Complications of endoscopic surgery of the pituitary adenomas: analysis of 570 patients and review of the literature. Pituitary 2012;15:288-300.

7 Park YS, Jung JY, Ahn JY, et al. Emergency endovascular stent graft and coil placement for internal carotid artery injury during transsphenoidal surgery. Surg Neurol 2009:72:741-6.

8 Cappabianca P, Briganti F, Cavallo LM, et al. Pseudoaneurysm of the intracavernous carotid artery following endoscopic endonasal transsphenoidal surgery, treated by endovascular approach. Acta Neurochir (Wien) 2001;143:95-6.

9 Kocer N, Kizilkilic O, Albayram S, et al. Treatment of iatrogenic internal carotid artery laceration and carotid cavernous fistula with endovascular stent-graft placement. AJNR Am J Neuroradiol 2002;23:442-6.

10 Zada G, Cavallo LM, Esposito F, et al. Transsphenoidal surgery in patients with acromegaly: operative strategies for overcoming technically challenging anatomical variations. Neurosurg Focus 2010;29:E8.

11 Park $\mathrm{AH}$, Stankiewicz JA, Chow J, et al. A protocol for management of a catastrophic complication of functional endoscopic sinus surgery: internal carotid artery injury. Am J Rhinol 1998;12:153-8.

12 Valentine R, Wormald PJ. Carotid artery injury after endonasal surgery. Otolaryngol Clin North Am 2011;44:1059-79.

13 Ghatge SB, Modi DB. Treatment of ruptured ICA during transsphenoidal surgery. Two different endovascular strategies in two cases. Interv Neuroradiol 2010;16:31-7.

14 Fukushima T, Maroon JC. Repair of carotid artery perforations during transsphenoidal surgery. Surg Neurol 1998;50:174-7.

15 Leung GK, Auyeung KM, Lui WM, et al. Emergency placement of a self-expandable covered stent for carotid artery injury during trans-sphenoidal surgery. $\mathrm{Br} \mathrm{J}$ Neurosurg 2006;20:55-7. 


\section{Head and neck}

16 Kwon OK, Lee KJ, Han MH, et al. Intraarterially administered abciximab as an adjuvant thrombolytic therapy: report of three cases. AJNR Am I Neuroradiol 2002;23:447-51.

17 Fiorella D, Albuquerque FC, Han P, et al. Strategies for the management of intraprocedural thromboembolic complications with abciximab (ReoPro). Neurosurgery 2004;54:1089-97.
18 Lawson MF, Fautheree GL, Waters MF, et al. Acute intraprocedural thrombus formation during wingspan intracranial stent placement for intracranial atherosclerotic disease. Neurosurgery 2010;67(Suppl Operative 3):ons166-70.

19 Amenta PS, Starke RM, Jabbour PM, et al. Successful treatment of a traumatic carotid pseudoaneurysm with the Pipeline stent: case report and review of the literature. Surg Neurol Int 2012;3:160. 